\title{
Consensus of German Transplant Centers on Hematopoietic Stem Cell Transplantation in Fanconi Anemia
}

\author{
Konsensus Empfehlungen Deutscher Transplantationszentren zur \\ hämatopoetischen Stammzelltransplantation bei Fanconi Anämie
}

\author{
Authors \\ Affiliations \\ M. M. Chao', W. Ebell ${ }^{2}$, P. Bader ${ }^{3}$, R. Beier', B. Burkhardt', T. Feuchtinger ${ }^{5}$, R. Handgretinger ${ }^{5}$,

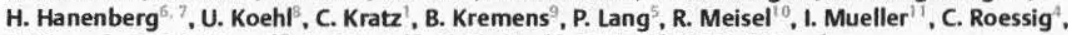 \\ M. Sauer', P. G. Schlegel' ${ }^{12}$, A. Schulz ${ }^{13}$, B. Strahm ${ }^{14}$, F. Thol' ${ }^{15}$, K. W. Sykora \\ Affiliation addresses are listed at the end of the article
}

\author{
Key words \\ fanconi anemia \\ o stem cell transplantation \\ consensus \\ recommendations \\ Schlüsselwörter \\ - Fanconi Anämie \\ - Stammzelltransplantation \\ o Konsensus \\ Empfehlungen
}

\begin{abstract}
$\nabla$

Allogeneic hematopoietic stem cell transplantation (HSCT) is currently the only curative therapy for the severe hematopoietic complications associated with Fanconi anemia (FA). In Germany, it is estimated that $10-15$ transplants are performed annually for FA. However, because FA is a DNA repair disorder, standard conditioning regimens confer a high risk of excessive regimen-related toxicities and mortality, and reduced intensity regimens are linked with graft failure in some FA patients. Moreover, development of graft-versus-host disease is a major contributing factor for secondary solid tumors. The relative rarity of the disorder limits HSCT experience at any single center. Consensus meetings were convened to develop a national approach for HSCT in FA. This manuscript outlines current experience and knowledge about HSCT in FA and, based on this analysis, general recommendations reached at these meetings.
\end{abstract}

\section{Introduction \\ $\nabla$}

Fanconi anemia (FA) is a rare inherited genomic instability disorder associated with congenital abnormalities, progressive bone marrow failure (BMF), and a predisposition to develop malignancies including myelodysplastic syndrome (MDS)/ acute myeloid leukemia (AML) and squamous cell carcinoma (SCC) [23,41]. Although there is phenotypic variability among FA individuals, hematologic abnormalities arise in the majority of patients and represent a significant clinical feature of the disorder. Some FA patients have mild hematologic changes and do not require thera-

\section{Zusammenfassung \\ $\nabla$}

Die allogene Stammzelltransplantation (HSCT) ist zurzeit die einzige kurative Therapie der schweren hämatopoetischen Komplikationen der Fanconi-Anämie (FA). In Deutschland werden etwa 10-15 Transplantationen pro Jahr bei Patienten mit FA durchgeführt. Da die FA auf einem Defekt der DNA-Reparatur beruht, können Standard-Konditionierungsprotokolle zu hoher Toxizität und Mortalität führen, während Regime mit reduzierter Intensität ein Risiko für Transplantatversagen in sich tragen. Hinzu kommt, dass die Entwicklung der Transplantat-gegenEmpfänger-Erkrankung ein wichtiger Risikofaktor für die Entwicklung von sekundären soliden Tumoren ist. Die relative Seltenheit der Erkrankung führt dazu, dass die Erfahrung jedes einzelnen Transplantationszentrums mit der Erkrankung begrenzt ist. Konsensus-Treffen mit dem Ziel der Entwicklung eines bundesweiten Vorgehens bei der Transplantation der FA wurden abgehalten. Dieses Manuskript beschreibt die langjährige Erfahrung und den aktuellen Kenntnisstand zur Transplantation bei FA sowie den darauf basierenden Konsens, der auf diesen Treffen erzielt wurde.

peutic intervention. Others have moderate to severe BMF that improves with androgen therapy [60]. In patients with BMF who fail to respond to androgens or who develop myeloid neoplasia, allogeneic hematopoietic stem cell transplantation (HSCT) can restore normal hematopoiesis. Unfortunately, early FA HSCT preparative regimens (cyclophosphamide \pm radiation) based on HSCT for patients with acquired severe aplastic anemia (SAA) were fraught with severe complications $[25,27,28,31,32,45]$. Excessive regimenrelated toxicities (RRT), high rates of graft failure, graft-versus-host-disease (GVHD), secondary cancers, and poor survival outcomes were ob- 
served. These were attributed to underlying congenital abnormalities, hypersensitivity to DNA damaging agents and putatively radiotherapy, delayed or absent tissue repair after GVHD induced injury, and/or presence of T cell mosaicism in some FA individuals. $[25,27,28,31,32,45]$.

Over the past 3 decades, modifications to FA HSCT conditioning regimens together with advances in transplant medicine (e.g. more accurate HLA typing, better supportive care, graft processing, etc.) have dramatically improved the prognosis of FA HSCT $[20]$. Reduction of chemotherapy and radiation doses (reduced intensity conditioning) lessened RRTs $[27,63]$. Incorporation of fludarabine to preparative regimens enhanced immunosuppression and engraftment without adding toxicity $[8,29,39,68]$. In vivo and/or ex vivo $T$ cell depletion of allografts decreased the incidence and severity of GVHD $[8,17]$. Radiation was eliminated in some conditioning regimens with excellent results $[48,54]$. For some FA HSCTs, particularly in HLA matched sibling donor (MSD) transplants, survival now ranges from $70-100 \%$ with low graft failure and GVHD rates [48].

Challenges, however, remain. For FA patients who do not have a MSD and receive transplants from either mismatched related or unrelated donors, collectively termed alternative donor (AD), the outcomes of HSCT are less encouraging, albeit improving [68]. FA patients with advanced MDS or AML have a poorer prognosis [2]. Post-transplant infections represent a leading cause of transplant related morbidity and mortality [10] (Chao et al. in press). Long-term follow-up of FA patients indicate a 4.4 fold increased risk of developing head and neck SCC after HSCT [59], associated with GVHD development and debatably radiation exposure $[15,32,59]$. These challenges provide incentive for further improvements in FA HSCT.

\section{Overview of FA HSCT nationally and internationally \\ $\nabla$}

The first HSCTs for FA in Germany were completed at the University of Ulm in the mid-1980s. Whereas the initial conditioning regimens included total body irradiation (TBI) or total lymphoid irradiation (TLI), since 1991, radiation has been eliminated. To date, 14 patients [ 6 matched unrelated(MUD), 5 MSD, 2 matched related transplants (MRD), and one haploidentical transplant] have received a cyclophosphamide fludarabine based regimen without radiation at the University of Ulm. Busulfan was also administered in patients with clonal disease and in the haploidentical transplant and anti-lymphocyte therapy with alemtuzumab (Campath-1H) or anti-thymocyte globulin (ATG) was applied in all patients except in those receiving MSD transplants. 10 of the 14 patients are alive, but unfortunately, 2 of the surviving patients are suffering from carcinomas.

Between October 1999 and April 2014, the Pediatric Blood and Marrow Transplantation Department at Charité University Medicine Berlin completed 39 consecutive $\operatorname{MSD}(n=4)$ and $A D$ $(n=35)$ HSCTs for FA. These transplants account for the majority of FA HSCTs performed in Germany. HSCT regimens titled German Fanconi Anemia 02 (GEFA02) $(n=18)$ and German Fanconi Anemia 03 (GEFA03) (Chao et al. in press) $(n=21)$, consisting of fludarabine based non-radiation conditioning, were utilized. The GEFA02 preparative regimen included fludarabine $30 \mathrm{mg} /$ $\mathrm{m}^{2} /$ day IV $\times 6$ days, busulfan $1 \mathrm{mg} / \mathrm{kg} /$ day in 2 divided doses PO $\times 2$ days, ATG-Fresenius $20 \mathrm{mg} / \mathrm{kg} /$ day IV $\times 3$ days, and $\mathrm{Mu}-$ romonab-CD3 (OKT3, Orthoclone OKT3) $0.1 \mathrm{mg} / \mathrm{kg} /$ day IV $\times 12$ days and was employed from 1999 to 2005 . Since 2005 to the present time, the GEFA03 regimen which includes fludarabine $30 \mathrm{mg} / \mathrm{m}^{2} /$ day IV $\times 6$ days, busulfan $1 \mathrm{mg} / \mathrm{kg} /$ day in 2 divided doses $\mathrm{PO} \times 2$ days, cyclophosphamide $20 \mathrm{mg} / \mathrm{kg} /$ day IV $\times 2$ days, and alemtuzumab $5 \mathrm{mg} / \mathrm{m}^{2} /$ day $\times 1$ day followed by $10 \mathrm{mg} / \mathrm{m}^{2} /$ day IV $\times 3$ days has been used. Patients received Cyclosporine A (CSA) for GVHD prophylaxis. In this series, all but one patient experienced neutrophil engraftment. Mixed chimerism was observed in 4 patients who all converted to full donor chimerism after stem cell boost(s), and 4 second transplants were undertaken for graft failure. Approximately $38 \%$ of patients developed grade 1 acute GVHD (aGVHD), 10\% grade II aGVHD, and no grade III-IV aGVHD was observed. Among the evaluable patients, $17 \%$ developed mild chronic GVHD (cGVHD) and no patient experienced moderate or severe CGVHD. 11 patients died: 8 from viral infection, 2 from AML disease progression, and one from SCC. The 2-year probability of survival was $76 \%$ (SE 7\%) with a median follow-up of 5.7 years. A sub-analysis of GEFA03 patients showed a 2 -year probability of survival of $90 \%, 100 \%$ neutrophil engraftment, $38 \%$ grade I aGVHD and no grade II-IV aGVHD, and no moderate or severe cGVHD.

At Eberhard Karl University in Tuebingen, 7 pediatric patients were transplanted for FA in more recent years. There were 4 MUD, 2 MSD, and one haploidentical donor transplants. The conditioning regimen included fludarabine $40 \mathrm{mg} / \mathrm{m}^{2} /$ dose $\times 4$ doses, cyclophosphamide $300 \mathrm{mg} / \mathrm{m}^{2} /$ dose $\times 4$ doses, and ATG Thymoglobulin $4.5 \mathrm{mg} / \mathrm{kg}$ total dose $(0.5-2-2 \mathrm{mg} / \mathrm{kg})$. For MUD transplants the dose of ATG was increased to $10 \mathrm{mg} / \mathrm{kg}$ (1-3$3-3 \mathrm{mg} / \mathrm{kg}$ ). For the haploidentical transplant, $15 \mathrm{mg} / \mathrm{kg}$ ATGFresenius (1-4-5-5 mg/kg) was used and $4 \mathrm{~Gy}$ TBI, followed by a TCR $\alpha \beta / C D 19$ negative depleted allograft of PBSCs. For MSD and MUD transplants, the GVHD prophylaxis included CSA and mycophenolate mofetil (MMF) and for the haploidentical transplant the patient received only MMF. All patients engrafted. 3 patients experienced aGVHD and among these patients, 2 developed grade I aGVHD and one grade III aGVHD. To date, only one patient has developed mild cGVHD. The overall survival was $100 \%$.

The German experiences recapitulate worldwide FA HSCT experiences (e.g. a retreat from radiation based conditioning, utilization of fludarabine and anti-lymphocyte antibodies, and use of new stem cell sources such as haploidentical donors). Current conditioning regimens used in Germany are comparable to preparative regimens employed by others elsewhere and confer good outcomes. FA HSCT results published in the past 5 years are detailed in $\bigcirc$ Table 1 [1,4,12, 19, 34, 46-48, 62,65, 67, 70, 71].

\section{Radiation vs, no radiation}

$\checkmark$

Historically, radiation was used in FA HSCT preparative regimens to facilitate engraftment. Yet, the early use of standard dose radiation was associated with severe adverse side effects and initial studies suggesting a marked hypersensitivity of FA patients towards radiation led to significant reduction of the radiation dose $[25,27]$. Elimination of the modality proved successful in MSD transplants. Here, graft failure was less problematic and radiation was omitted without compromising engraftment. In mismatched and unrelated donor FA HSCTs, radiation was replaced by busulfan in some centers with good results [12]. Other centers have continued to employ radiation at lower doses for mismatched and unrelated donor transplants, arguing that single fraction low-dose radiation confers minimal toxicities not exceeding busulfan related toxicities $[47,48]$. In Germany, radia- 


\begin{tabular}{|c|c|c|c|c|c|c|c|c|}
\hline Reference & $\begin{array}{l}\text { Conditioning } \\
\text { Regimen }\end{array}$ & GVHD Prophy & No. of Cases & $\begin{array}{l}\text { Median } \\
\text { Age }\end{array}$ & $\begin{array}{l}\text { Engraft- } \\
\text { ment * }\end{array}$ & aGVHD & CGVHD & Survival \\
\hline Ayas et al. 2012 [1] & Cy, Flu, ATC & CSA & 26 (19 MRD, 7 UCB) & $7.8 \mathrm{yrs}$ & $\begin{array}{l}19 / 19 \\
2 / 7\end{array}$ & $\begin{array}{l}1 / 19 \\
1 / 7\end{array}$ & $\begin{array}{l}1 / 19 \\
1 / 7\end{array}$ & $\begin{array}{l}100 \% \\
43 \% \text { OS }\end{array}$ \\
\hline $\begin{array}{l}\text { Shimada et al. } \\
2012 \text { [62] }\end{array}$ & Cy, Flu, ATG & $\begin{array}{l}\text { CSA, MTX; } \\
\text { FK506, MTX }\end{array}$ & $\begin{array}{l}8 \text { (3 MSD, } 1 \text { MRD, } \\
2 \text { MUD, } 2 \text { MMUD) }\end{array}$ & $4.5 \mathrm{yrs}$ & $8 / 8$ & $1 / 8$ & $0 / 8$ & $100 \%$ os \\
\hline Yabe et al. 2012 [70] & $\begin{array}{l}\text { Cy, ATC, TAI/TBI; } \\
\text { Cy, Flu, ATC }\end{array}$ & CSA, MTX & 15 (MSD) & $8 y r s$ & $14 / 15$ & $1 / 15$ & $3 / 14$ & $80 \%$ OS \\
\hline $\begin{array}{l}\text { Boulad et al. } \\
2012 \text { [12] }\end{array}$ & Cy, Bu, Flu, ATC & & $27(A D)$ & & $27 / 27$ & $3 / 27$ & & $83 \%$ OS \\
\hline $\begin{array}{l}\text { MacMillan et al. } \\
2012[46]\end{array}$ & Cy, ATG, TBI, \pm Flu & & $127(A D)$ & & & $\begin{array}{l}18-50 \% \\
\text { grade } \\
\text { II-IV }\end{array}$ & $9-25 \%$ & $\begin{array}{l}61 \% 1 \mathrm{yr} \\
\text { POS; } 54 \% \\
5 \text { yrs POS }\end{array}$ \\
\hline Thaker et al. 2011 [67] & Flu, TBI & CSA, MMF & $6(A D)$ & & $5 / 6$ & $4 / 6$ & $3 / 5$ & $50 \%$ os \\
\hline $\begin{array}{l}\text { Stepensky et al. } \\
2011 \text { [65] }\end{array}$ & $\begin{array}{l}\text { Cy, } \pm \text { TAI/ } \\
\text { Tul, } \pm \text { Bu, } \pm \text { ATC; } \\
\text { Flu } \pm \text { Cy, } \pm B u \\
\pm \text { ATG/Atgam, } \pm T B I\end{array}$ & $\begin{array}{l}\text { CSA; CSA, MMF; } \\
\text { Dac; CSA, Dac; } \\
\text { FK506, MMF, } \\
\text { Dac }\end{array}$ & $\begin{array}{l}41 \text { (MSD, AD; } \\
17 \text { w/o Flu, } 24 \text { w/ Flu) }\end{array}$ & $10.3 \mathrm{yrs}$ & $\begin{array}{l}17 / 17 \\
22 / 24\end{array}$ & $\begin{array}{l}14 / 17 \\
11 / 24\end{array}$ & $\begin{array}{l}4 / 17 \\
8 / 24\end{array}$ & $\begin{array}{l}35 \%, 83 \% \\
\text { OS }\end{array}$ \\
\hline $\begin{array}{l}\text { Hamidieh et al. } \\
2011[34]\end{array}$ & $\begin{array}{l}\text { Cy, Bu, } \pm \text { ATC; Cy. } \\
\text { Flu, ATC }\end{array}$ & CSA $\pm M T X$ & $\begin{array}{l}53 \text { (MSD, MRD, MMRD; } \\
42 \mathrm{w} / \mathrm{o} \text { Flu, } 11 \mathrm{w} / \mathrm{Flu} \text { ) }\end{array}$ & $9 y r s$ & $49 / 53$ & $\begin{array}{l}79 \% \\
45 \%\end{array}$ & $\begin{array}{l}17 \% . \\
36 \%\end{array}$ & $61 \%$ os \\
\hline $\begin{array}{l}\text { MacMillan et al. } \\
2010[48]\end{array}$ & Cy, Flu, ATG & & 22 (MSD) & $8.5 y r s$ & $22 / 22$ & $0 \%$ & $0 \%$ & $82 \%$ OS \\
\hline $\begin{array}{l}\text { MacMillan et al. } \\
2009 \text { [47] }\end{array}$ & Cy, Flu, TBI, ATG & CSA & $\begin{array}{l}24 \text { (AD; } 22 \text { w/ } 3 \text { Gy TBI, } \\
2 \text { w/ } 1.5 \text { Gy TBI) }\end{array}$ & $8.8 \mathrm{yrs}$ & $\begin{array}{l}22 / 22 \\
0 / 2\end{array}$ & $\begin{array}{l}3 / 22 \\
0 / 2\end{array}$ & & $\begin{array}{l}86 \% \\
100 \% \text { os }\end{array}$ \\
\hline Ertem et al. 2009 [19] & Cy, Bu; Cy, Flu, ATC & CSA, MTX & 8 (MSD) & $12 \mathrm{yrs}$ & $8 / 8$ & $0 / 8$ & $1 / 8$ & $87.5 \%$ OS \\
\hline Baker et al. 2009 [4] & Cy, Flu, ATG, \pm Bu & CSA, MP & 5 (MRD, MUD) & & $4 / 5$ & $2 / 5$ & $0 / 5$ & $80 \%$ os \\
\hline $\begin{array}{l}\text { Yesilipek et al. } \\
2009 \text { [71] }\end{array}$ & $\begin{array}{l}\text { Cy, TAl, ATG; Cy, } \\
\text { Flu, ATG }\end{array}$ & $\mathrm{CSA} \pm \mathrm{MMF}$ & $\begin{array}{l}16 \text { (MRD, MUD; } \\
6 \mathrm{TBI}, 10 \mathrm{Flu} \text { ) }\end{array}$ & & & & & $\begin{array}{l}50 \% .90 \% \\
\text { OS }\end{array}$ \\
\hline
\end{tabular}

tion has been omitted for MSD, MUD, and mismatched unrelated donor FA HSCTs (excluding some haploidentical transplants). Interestingly, conflicting experimental and clinical data regarding the radiosensitivity of FA has emerged. While Marcou et al. demonstrated normal colony survival assays in irradiated fibroblasts from a FA patient, Djuzenova et al. using the same patient's fibroblasts showed increased DNA damage after radiation exposure $[16,49]$. The patient experienced severe toxicities after radiotherapy for tonsillar carcinoma [49]. A newer study demonstrated that primary fibroblasts from patients with mutations in FANCA, FANCD2, and FANCG are not particularly sensitive for either ionizing or UV radiation [37]. Moreover, older studies clearly implicated radiation in the development of post-transplant head and neck SCC in FA patients [15], but more recent studies have not identified this link $[55,59]$. The consensus group addressed the question whether radiation might be reintroduced in future German FA transplant protocols. The group agreed to continue with non-radiation protocols based on (a) established experience with non-radiation FA HSCT protocols, (b) good results achieved with these protocols, (c) potential to eliminate any possible short- and long-term toxicities associated with radiation, and (d) recent large FA HSCT reviews suggesting inferior survival for FA patients treated with radiationcontaining preparative regimens $[3,55]$.

\section{The backbone}

$\mathrm{v}$

Early FA HSCT conditioning regimens consisted of cyclophosphamide $(200 \mathrm{mg} / \mathrm{kg})$ and radiation. With increasing experience, there have been refinements to the conditioning regimens. A 5-10 fold reduction in the cyclophosphamide dose was instituted. Likewise, radiation was decreased in dose or eliminated. Kapelushnik et al. were the first to report the use of fludarabine in FA HSCT [39]. Subsequently, numerous studies demonstrated that fludarabine accorded engraftment and survival benefits. Currently, fludarabine based regimens are regarded as standard in FA HSCTs $[8,14,65]$. Dose reduction of fludarabine, however, is warranted in FA patients with renal compromise (personal communication with W. Ebell). Might there be additional modification(s) to the FA HSCT preparative regimens to further reduce RRTs?

In 2007, Bonfim et al. reported on 43 FA patients who received transplants from HLA-matched related donors [11]. The conditioning regimen consisted of cyclophosphamide alone (total dose $60 \mathrm{mg} / \mathrm{kg}$ ). 40 patients ( $93 \%$ ) were alive with a median follow-up of 3.7 years. One patient experienced primary graft failure and 4 patients developed late graft failure. Grade II-III aGVHD and cGVHD were noted in 17 and $28.5 \%$ of patients, respectively [11]. A recently completed phase I/II study at Baylor College of Medicine in Houston, Texas, USA examined alemtuzumab and anti-CD45 antibodies (YTH-24 and YTH-54) (10/10 HLA matched) or alemtuzumab, anti-CD45 antibodies, and fludarabine ( $9 / 10 \mathrm{HLA}$ matched) conditioning in 5 pediatric patients with FA or other DNA breakage/chromosomal instability syndromes [51]. For HLA mismatched donors, harvested peripheral blood stem cells (PBSC) were enriched for CD34+cells [51]. 2 of the 5 participants showed donor engraftment at day +100 . Median time to ANC $>500 / \mathrm{mm}^{3}$ was 15 days. No aGVHD grade II-IV or CGVHD was observed and all patients are alive at one 
year post-transplantation [51]. At Boston Children's Hospital, Boston, Massachusetts, USA 4 patients with dyskeratosis congenita were successfully transplanted with matched unrelated donor allografts ( $\geq 9 / 10$ HLA matched) using fludarabine and alemtuzumab [43]. All patients engrafted neutrophils by day +30 , and are alive and transfusion independent with a follow-up ranging from 6 months ( 1 patient) to 2 years ( 3 patients) [43]. All patients showed full donor myeloid chimerism by day +60.3 of the 4 patients showed full donor lymphoid chimerism by year 2 , and the fourth patient has high and increasing mixed donor lymphoid chimerism at day +180 . There was no aGVHD and only one patient developed limited cGVHD of the skin [43]. Whether fludarabine and alemtuzumab only preparative regimen might be effective in FA HSCT is yet to be established.

Based on these and other published data and the German experience, particularly GEFA03, the consensus group agreed that fludarabine, cyclophosphamide, and busulfan will continue as the backbone agents; however, busulfan may be excluded in some transplants. Busulfan is unlikely to be necessary for "low risk" transplants (i.e. $\geq 9 / 10$ HLA matched related or unrelated HSCTs with BMF). Busulfan may be beneficial in FA patients with mismatched allografts to assist engraftment, and as an anti-leukemic agent in FA patients with bone marrow clonal aberration(s) and/or MDS/AML. Intravenous busulfan is preferred over oral busulfan due to its more consistent pharmacokinetics.

\section{in vivo T cell depletion: Anti-thymocyte globulins vs. alemtuzumab \\ $\nabla$}

Both $\operatorname{ATG}(\mathrm{s})$ and alemtuzumab have been applied as in vivo $\mathrm{T}$ cell depleting agents in FA HSCTs to aid engraftment and to reduce the incidence and severity of GVHD. Whether one lymphocyte-depleting antibody may be advocated over the other is difficult to answer, as there are no prospective direct comparison studies in FA. Charité University Medicine Berlin used ATG-Fresenius with OKT 3 in the GEFA02 protocol and alemtuzumab in the GEFA03 protocol. Comparison of GEFA02 and GEFA03 results, with the caveat that the backbone agents were not identical, demonstrated more stable engraftment $(5 / 18 \mathrm{vs}$. $0 / 21$ graft failure or mixed chimerism requiring stem cell boosts), less fatal viral infections (6/18 vs. 2/21), and a higher overall survival rate (10/18 vs. 18/21) with GEFA03. Moreover, published reports in other diseases and adult patients suggest superior outcomes with alemtuzumab. Marsh et al. retrospectively compared patients with acquired SAA who were conditioned for allogeneic HSCT with regimens including alemtuzumab $(n=100)$ or ATG $(n=55)$ [50]. Engraftment failure occurred in 9 and $11 \%$ of patients in the alemtuzumab and ATG groups, respectively. The 5 -year survival rate was $90 \%$ for alemtuzumab and $79 \%$ for ATG. Overall survival was significantly better when using alemtuzumab $(88 \%)$ compared with ATG $(57 \%, p=0.026)$ for unrelated donor transplants. The risk for CGVHD was lower in the alemtuzumab group (11 vs. $26 \%, p=0.031$ ) [50]. Similarly, Soiffer et al. examined the outcomes of reduced intensity conditioning transplants according to the use of in vivo T cell depletion with ATG $(n=584)$, alemtuzumab $(n=213)$, or no antibody therapy $(n=879)$ in patients with hematopoietic malignancies [64]. Both grade II-IV aGVHD and CGVHD incidences were lower with alemtuzumab compared with ATG and unmanipulated grafts ( 19 vs. $38 \%$ for ATG and $40 \%$ for unmanipulated grafts, $p<0.0001$ and 24 vs. $40 \%$ for ATG and $52 \%$ for unmanipulated grafts, $p<0.0001$, respectively) [64]. Relapse was more frequent with alemtuzumab and ATG (49 and 51\%, respectively, vs. $38 \%$ unmanipulated, $\mathrm{p}<0.001$ ). The 3-year probability of survival after adjusting for age, performance status, disease, disease status, GVHD prophylaxis, and donor source were $50 \%$ for alemtuzumab, $46 \%$ for T cell replete, and $38 \%$ for ATG containing regimens. The difference in survival outcomes between alemtuzumab and $T$ cell replete groups was not statistically significant but the difference between ATG and unmanipulated T cell replete grafts was significant $(p=0.008)$ [64]. Lower incidences of GVHD and RRTs and their sequelae related with alemtuzumab administration may explain the improved survival rates [47]. Of significance for FA patients is the lower rate of GVHD afforded by alemtuzumab, since its development is associated with a higher risk for secondary malignancy [59] and a negative impact on the quality of life.

\section{Other GVHD prophylaxis}

$\nabla$

In a retrospective review of patients with $F A(n=37)$ or acquired aplastic anemia $(n=73)$ following MSD HSCT, FA patients had double the relative risk of grades II-IV aGVHD $(p=0.021)$, and in younger patients, the relative risk was $7.93(p=0.014)$ [32]. Moreover, the risk of requiring systemic corticosteroids and experiencing steroid-resistant aGVHD was higher in FA patients [32]. Increased cellular apoptosis in FA individuals has been linked to the higher severity of aGVHD [69]. Wang et al. assessed epithelial cell apoptosis and studied TP53 and miR-34a expression in the skin and gut biopsies from 5 non-transplanted FA patients, 20 FA patients with aGVHD, and 25 acquired aplastic anemia patients. Although FA and aplastic anemia patients received similar preparative regimens, epithelial apoptosis was higher in FA specimens than in samples from patients with acquired aplastic anemia patients [69]. Further studies of gut biopsies from FA patients showed that this deleterious effect was not related to TP53 gene overexpression but rather miR-34a which mimics p53 apoptotic effects in response to DNA damage [69]. In a large analysis of 795 FA HSCTs between 1972 and 2009, the incidence of cGVHD was $14 \%$ at 1 year and $19 \%$ at 5 years [55]. Older age at transplant and history of aGVHD were independent predictors of cGVHD [55]. The development of cGVHD correlated with an increased risk of developing head and neck SCC [59]. A principal goal in FA HSCT has been to reduce the incidence and severity of GVHD in order to abolish any of its potential shortand long-term complications. In addition to anti-lymphocyte antibody to reduce the incidence and severity of GVHD, the consensus group advises CSA as GVHD prophylaxis, with the addition of MMF for unrelated donors.

\section{Immune reconstitution}

\%

Allogeneic HSCT is associated with profound immune deficiency owing to a multitude of factors including underlying disease, transplant conditioning regimen, stem cell source, degree of HLA matching, graft manipulation, development of GVHD, immunosuppressive medications for GVHD prophylaxis/therapy, and others. However, the speed of immune recovery has important repercussions regarding infectious complications and relapse following allogeneic HSCT $[21,40]$. The consensus group addressed post-transplant immune reconstitution as related to the 
anti-lymphocyte antibody utilized in the preparative regimen. The focus was on alemtuzumab since the antibody is proposed for future studies.

There is evidence that alemtuzumab is more immunosuppressive than ATG because the former is directed against a variety of immune cells including $T$ and $B$ cells, macrophages, monocytes, and NK cells and the latter targets mainly T lymphocytes [57]. In a comparison of immune reconstitution following alemtuzumab $(n=14)$ or ATG $(n=13)$ in pediatric unrelated transplants, patients who received alemtuzumab demonstrated significantly slower immune recovery [61]. The presence of peripheral blood $\mathrm{CD} 3+\mathrm{T}$ cells ( $>30$ cells $/ \mu \mathrm{L})(64.5$ vs. 27 days), the median time to normal phytohemagglutinin response ( 283 vs. 88 days), and the median time to an antigen specific response ( 365 vs. 150 days) occurred later in those receiving alemtuzumab in comparison to patients given ATG [61]. Despite these delays in immune recovery, there was no increase in infectious complications in recipients of alemtuzumab [61].

Total lymphocyte and lymphocyte subset counts in peripheral blood were evaluated in the 39 patients who received GEFA02 (ATG/OKT3) and GEFA03 (alemtuzumab) preparative regimens. There was large patient-to-patient variability related to the clinical circumstance of the patient; however, as a group, total lymphocyte counts steadily rose and by day +100 the mean value was $1166 / \mu \mathrm{L}$. NK cells were present at normal numbers immediately following transplantation and accounted for the majority of lymphoid cells during the early post-transplant period. B cells reached normal levels by day +60 . CD8 + cells recovered by 3 months. CD4 $+\mathrm{T}$ cells were considerably slower to recover and the $C D 4+$ to $C D 8$ + ratio remained $<1$ in the majority of patients during the first year following transplantation. $C D 4+$ reached normal levels by day +365 . Memory $(C D 45 R O+)$ helper $(C D 4+)$ and cytotoxic $(C D 8+) T$ cells predominated over naïve (CD45RA+) $T$ cells during the one-year analysis period. Comparison of GEFA02 and GEFA03 immune reconstitution data showed modestly higher lymphocyte values for GEFA03 patients that were not statistically significant for most of the analyzed time points. This pattern of post-transplantation immune reconstitution is similar but not identical to reports by others $[24,56]$. In FA patients following HSCT, Perlingeiro et al. found a slightly different kinetic of recovery in the major lymphocyte subsets in 23 patients conditioned with one of 3 regimens (fludarabine, cyclophosphamide and ATG, cyclophosphamide alone, or fludarabine and irradiation) for related and unrelated donor transplants [56]. NK cells were the first to recover, followed by cytotoxic $C D 8+T$ cells and B cells, and finally CD4+T cells. Early lymphocyte recovery consisted of memory cells potentially derived from the graft. New thymic emigrant $(C D 31+C D 45 R A+)$ and naive CD4+or CD8+T cells rose only at 6 months after HSCT. Only marginal differences were observed in the early recovery of CD8 + T cells among those receiving a graft from a related donor versus an unrelated donor. Patients with GVHD displayed a markedly delayed recovery of NK cells and B cells as well as of regulatory $T$ cells and both early thymic emigrant and total CD4 + T cells [56]. Nonetheless, viral infection represented a major complication following FA allogeneic transplantation [10]. Indeed, in the Charite University Medicine Berlin cohort $(n=39)$, viral reactivation/infection involving $\mathrm{CMV}$, human herpes virus 6 , Epstein-Barr virus (EBV), adenovirus, and combined viral infections, were the leading causes of death (8/11).

A logical response to improve post-transplant immune recovery may be to decrease the dose of alemtuzumab. A wide range of doses (100-10 mg total dose) of alemtuzumab has been employed in allogeneic HSCT $[38,57]$. Chakraverty et al. examined de-escalating doses of alemtuzumab in reduced intensity conditioning regimen with fludarabine and melphalan in 106 adult MSD transplants [13]. The $20 \mathrm{mg}$ total dose of alemtuzumab was associated with a greater risk of grade III-IV aGVHD and severe cGVHD in comparison with doses $>20 \mathrm{mg}$. A total dose of $20 \mathrm{mg}$ or lower was linked with incomplete saturation of CD52 binding sites, more rapid clearance, and greater risk of severe acute and chronic GVHD $[13,57]$. A total dose of $30 \mathrm{mg}$ or lower was associated with a significant decrease in alemtuzumab levels by day 28 $[13,57]$. The $30 \mathrm{mg}$ dose resulted in comparable GVHD outcomes but better lymphocyte recovery at one year post-transplantation than the $40 \mathrm{mg}$ or $60 \mathrm{mg}$ dose groups [13]. However, improved lymphocyte counts were not associated with lower rates of infections [13]. Bertz et al. reported no difference in grade III-IV aGVHD and extensive CGVHD or graft failure in 127 patients who received 10,20 , or $40 \mathrm{mg}$ (total dose) alemtuzumab for unrelated transplants [7]. There was a significant difference in grade II-IV aGVHD incidence between the 20 and $40 \mathrm{mg}$ dose cohorts [7]. In summary, the standard total dose of $100 \mathrm{mg}$ appears more than is required in most transplant settings. Doses of less than $30 \mathrm{mg}$ may be insufficient and predispose to increased risks of GVHD [57], however, comparative analyses of data from published literature are difficult due to differences in patient populations, diseases treated, and preparative regimens. Still more, the clinical benefit (i.e. decreased infections) is unclear. Finally, Bokhari et al. reported increased incidence of EBV induced post-transplant lymphoproliferative disease (PTLD) following a reduction in alemtuzumab dose from 50 to $30 \mathrm{mg}$ [9]. For comparison, the alemtuzumab dose of $35 \mathrm{mg} / \mathrm{m}^{2}(1.16 \mathrm{mg}$ / $\mathrm{kg}$ ) used in GEFA03 resulted in a median total dose of $35 \mathrm{mg}$ and mean total dose of $38 \mathrm{mg}$ (range $11-75 \mathrm{mg}$ ). Other reduced intensity conditioning regimens for HSCT in patients with chronic granulomatous disease or DNA breakage repair disorder use alemtuzumab doses ranging from $0.5 \mathrm{mg} / \mathrm{kg}$ to $1 \mathrm{mg} / \mathrm{kg}[30,33]$. The consensus group agreed to an alemtuzumab dose of $30 \mathrm{mg} /$ $\mathrm{m}^{2}(1 \mathrm{mg} / \mathrm{kg}$ ), since further dose reductions appear not to provide anti-infection benefits and may increase the risk of GVHD. A decreased alemtuzumab dose of $20 \mathrm{mg} / \mathrm{m}^{2}$ may be employed in patients with MSD allografts (10/10, genotypically identical), only of BM is used as stem cell graft. In patients with MSD allografts $(\geq 9 / 10)$ and PBSC grafts, total alemtuzumab dose should remain $30 \mathrm{mg} / \mathrm{m}^{2}$, due to increased risk of GVHD. The group also advocates prophylaxis and strict surveillance of infections, preemptive therapy and aggressive early treatment.

Selective allodepletion of the graft may be one method to improve immune reconstitution following allogeneic HSCT. CD34 + positive selection of stem cell grafts enabled rapid and sustained engraftment, but immune reconstitution was delayed due to non-discriminate reduction of T cells in donor grafts [5]. Development of CD3, CD3/CD19 and more recently TCR $\alpha \beta / C D 19$ depletion strategies allow for $\mathrm{T}$ cell depletion of allografts with preservation of immune effector cells such as NK cells, monocytes, dendritic cells, and $\gamma \delta \mathrm{T}$ cells to improve immune recovery and to better exploit graft versus malignancy effects [35]. In a randomized study of MSD and unrelated donor transplants, faster NK cell recovery was observed in patients with CD3/CD19 depleted PBSC grafts as compared with the CD34 positive selection patients [35]. Lang et al. recently reported on the results of 35 patients with high-risk malignant and nonmalignant disorders transplanted with TCR $\alpha \beta / C D 19$ depleted haploidentical 
grafts. Within the first month post-transplantation, rapid immune reconstitution with good levels of $C D 3+T$ cells, CD3 + CD4 $+\mathrm{T}$ cells, and CD56 + NK cells was observed [42]. In addition, expansion of $T C R \gamma \delta+T$ cells occurred faster than $T C R \alpha \beta+T$ cells in the early post-transplant period and may contribute to anti-infectious and anti-tumor immunity [42,44,53]. Graft engineering technologies may benefit FA patients, especially if they receive a mismatched PBSC allograft.

\section{Haploidentical transplantation}

In patients who lack an HLA matched related or unrelated donor, haploidentical stem cell transplantation is a feasible alternative. The immediate availability of a haploidentical donor in most families and the possibility for post-transplant cellular therapies either in the prevention of relapse or treatment of viral infections by adoptive $\mathrm{T}$ cell transfer are advantages of this type of transplantation [52]. Haploidentical HSCTs have been undertaken for both malignant and nonmalignant disorders since the late 1970 s $[6,22,58]$. In a recent publication, Zecca et al. reported on 12 FA patients who were given T cell depleted, CD34 + positively selected cells from a haploidentical related donor after a reduced intensity conditioning regimen including fludarabine $\left(120 \mathrm{mg} / \mathrm{m}^{2}\right)$, cyclophosphamide $\left(1200 \mathrm{mg} / \mathrm{m}^{2}\right)$, ATG-Fresenius $(40 \mathrm{mg} / \mathrm{kg}$ ) with and without radiation (2 Gy TBI) [72]. Engraftment was achieved in 9 of 12 patients ( $75 \%$ ) and the cumulative incidence of graft rejection was 17\% (95\% confidence interval [CI], 5-59\%). The frequencies of grades II-IV aGVHD and cGVHD were $17 \%$ (95\% CI, 5-59\%) and $35 \%(95 \% \mathrm{CI}, 14-89 \%)$, respectively. The cumulative incidence of transplant-related mortality was $17 \%$ ( $95 \% \mathrm{CI}, 5-59 \%)$. The 5-year overall survival, event-free survival (probability of survival from time of transplant to occurrence of any event- graft failure, rejection or death from any cause- or the date of last follow up), and disease-free survival (probability of survival without evidence of disease at anytime after transplantation) were $83 \%(95 \% \mathrm{Cl}, 62-100 \%), 67 \%(95 \% \mathrm{Cl}$, $40-93 \%)$, and $83 \%(95 \% \mathrm{Cl}, 62-100 \%)$, respectively [72]. Another group published their experience with 3 FA haploidentical HSCTs [66]. The patients received cyclophosphamide, fludarabine, and radiation. All 3 patients engrafted. One patient died from infection on day +37 . Of the 2 remaining patients, both developed $\geq$ grade II aGVHD and one patient developed mild CGVHD [66]. Dufort et al. also reported on 3 FA patients who were given fludarabine, cyclophosphamide, ATG, and TLI prior to haploidentical transplantation [18]. The patients engrafted, did not experience GVHD, and are alive at last follow-up (5, 6, and 16 months) [18].

Charité University Medicine Berlin performed one haploidentical transplant for FA using the GEFA03 conditioning regimen. The patient had MDS classified as refractory anemia with $7 \%$ blasts and complex karyotype including a chromosome 3 abnormality. He received CD34+ positively selected PBSC from a paternal uncle and engrafted neutrophils and platelets. The patient did not experience any aGVHD, but did develop mild cGVHD. Approximately 18 months post-transplantation, the marrow showed recipient marrow reconstitution and progression to AML. The patient subsequently received multiple donor lymphocyte infusions, reinduction chemotherapy, and a second haploidentical transplant from his father. He eventually died of AML 8 years after the first transplantation. At Hannover Medical School Children's Hospital, one FA patient with AML underwent a paternal haploidentical HSCT. The patient received pre-transplantation therapy with low-dose cytarabine and developed prolonged aplasia and pulmonary aspergillosis. The patient went on to receive a megadose of $\mathrm{CD} 34+$ positively selected PBSC and granulocyte transfusions until engraftment after conditioning with cyclophosphamide, fludarabine, and ATG. She developed mild cGVHD involving her skin and is alive and well 15 years after transplantation. In Tuebingen, one FA patients received a haploidentical transplants from a paternal grandmother. Here, the conditioning regimen included cyclophosphamide, fludarabine, ATG, irradiation, and TCR $\alpha \beta / C D 19$ depletion of the graft. The patient engrafted neutrophils and platelets. The patient developed grade I aGVHD but no cGVHD and is alive. Haploidentical transplantation in $\mathrm{FA}$ is emerging as an alternative therapy for some FA patients. There appears to be more experience using ATG in this setting. Concepts using post stem cell infusion cyclophosphamide for $\mathrm{T}$ cell allodepletion are being developed for FA patients receiving mismatched allografts including haploidentical transplants [66].

\section{Cord blood transplantation}

$\nabla$

Although the first successful related cord blood transplantation (CBT) occurred in a patient with FA [26], there is a paucity of information regarding FA patients and CBT. EBMT retrospectively analyzed the results of unrelated cord blood transplantation (UCBT) in $93 \mathrm{FA}$ patients from 26 centers worldwide transplanted between 1994 and 2005 [29]. The median age at transplantation was 8.6 years. The majority of patients received an HLA mismatched cord blood allograft ( 1 HLA difference 35 cases and 2 or 3 HLA differences 45 cases). The median number of nucleated cells and CD34+cells infused was $4.9 \times 10^{7} / \mathrm{kg}$ and $1.9 \times 10^{5} / \mathrm{kg}$, respectively. The transplants were completed using varying preparative regimens; $61 \%$ of patients received fludarabine [29]. Cumulative incidence of neutrophil recovery was $60 \pm 5 \%$ at day +60 . The incidence of grade II-IV aGVHD and cGVHD was $32 \pm 5 \%$ and $16 \pm 4 \%$, respectively. Overall survival was $40 \pm 5 \%$. In multivariate analysis, factors associated with favorable outcome were use of fludarabine in the conditioning regimen, $\geq 4.9 \times 10^{7} / \mathrm{kg}$ nucleated cells infused, and negative recipient CMV serology [29]. More recent reports describe small institutional experiences and demonstrate conflicting results. Ayas et al. reported on $7 \mathrm{FA}$ patients who received partially matched unrelated cord blood grafts. The patients were conditioned with cyclophosphamide ( $5 \mathrm{mg} / \mathrm{kg} /$ day for 4 days), fludarabine $\left(30 \mathrm{mg} / \mathrm{m}^{2} /\right.$ dose for 5 days), and rabbit ATG ( $5 \mathrm{mg} / \mathrm{kg} /$ day for 4 days) [1]. The therapy was generally well tolerated with mucositis and CMV viremia representing major therapy-related complications [1]. 4 patients failed to engraft and another patient had secondary graft failure 7 months post-transplantation. One patient developed grade II aGVHD of the skin that evolved to cGVHD. At last follow-up ranging from 29 to 34 months, 3 patients are alive but only 2 are transfusion independent [1]. Jaing et al. administered fludarabine $(30 \mathrm{mg} / \mathrm{m} /$ day for 6 days), cyclophosphamide $(60 \mathrm{mg} / \mathrm{kg} /$ day for 2 days), and rabbit ATG ( $2.5 \mathrm{mg} / \mathrm{kg} /$ day for 3 days $)$ in $3 \mathrm{FA}$ patients who received unmanipulated umbilical cord blood allografts [36]. None of the patients developed significant regimen related toxicity and all engrafted within 10-19 days [36]. All patients are well with stable or full donor chimerism after a median follow-up of 64 months [36]. In summary, CBT in FA is evolving. 


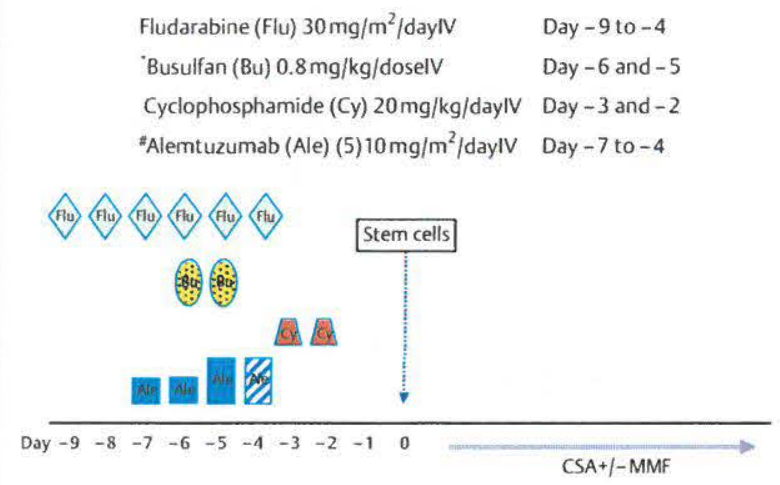

Fig. 1 Recommended allogeneic hematopoietic stem cell transplantation schema based on GEFA03. * Omit busulfan for low risk patients defined as cytopenia without evidence of leukemia or cytogenetic aberrations and with HLA identical donor (i.e. 29/10 MSD, MRD, or MUD). Busulfan levels recommended. \#Decrease alemtuzumab dose to $20 \mathrm{mg} / \mathrm{m}^{2}$ in patients with MSD allografts (10/10) and only if BM is used as stem cell source. In patients with MSD ( $\leq 9 / 10)$, unrelated donor, or PBSC grafts, total alemtuzumab dose should remain $30 \mathrm{mg} / \mathrm{m}^{2}$.

The total dose of conditioning drugs is: fludarabine $180 \mathrm{mg} / \mathrm{m}^{2}$. IV busulfan (Busilvex ${ }^{8}$ ) $1.6 \mathrm{mg} / \mathrm{kg}$, cyclophosphamide $40 \mathrm{mg} / \mathrm{kg}$, and alemtuzumab $30 \mathrm{mg} / \mathrm{m}^{2}$ for MUD, MMRD, or PBSC $\left(5 \mathrm{mg} / \mathrm{m}^{2}\right.$ days -7 and -6 followed by $10 \mathrm{mg} / \mathrm{m}^{2}$ days -5 and -4$)$ reduced to $20 \mathrm{mg} / \mathrm{m}^{2}$ for $M S D\left(5 \mathrm{mg} / \mathrm{m}^{2}\right.$ days -7 and -6 followed by $10 \mathrm{mg} / \mathrm{m}^{2}$ day -5 ).

\section{Conclusions and recommendations}

$$
\nabla
$$

HSCT represents a curative option for the severe hematological complications associated with FA. The therapeutic procedure is, however, characterized by unique challenges in this patient population. The consensus meetings on HSCT in FA aims to build upon previous German and international experiences and incorporate new data and technologies to improve outcomes. The current conclusions and recommendations are as follows:

1. Chemotherapy-only conditioning regimens resulted in equal or better outcomes than regimens that included radiotherapy, also in patients with MDS/AML. There is no reason to reintroduce radiotherapy into conditioning regimens for FA.

2. The chemotherapeutic backbone in the German GEFA03 study, the ESID-EBMT recommendations, and other modern conditioning therapies consist of fludarabine and cyclophosphamide [30]. This combination also forms the basis of the current recommendation. Fig. 1 illustrates the preparative regimen.

3. The addition of busulfan to the fludarabine cyclophosphamide backbone is probably not necessary in patients transplanted for BMF without blood cell clonal aberration(s) and/ or MDS/AML, if transplanted from a $\geq 9 / 10$ HLA matched related or unrelated donor.

4. Busulfan is recommended to facilitate engraftment in patients with mismatched/haploidentical allografts $(<9 / 10)$ and as anti-leukemic agent in patients with bone marrow clonal aberrations and/or MDS/AML. The intravenous formulation is preferred due to more consistent blood levels. To gain more knowledge about the pharmacology of busulfan in FA, pharmacological monitoring of busulfan levels is recommended.

5. To prevent GVHD, in vivo $\mathrm{T}$ cell depletion is recommended in all FA patients, including patients transplanted from an MSD.
6. Alemtuzumab is considered superior to ATG in FA patients because of its better GVHD prophylactic effect.

7. In addition to anti-T cell antibody, CSA (day - 1 until day +100 , then taper) is employed for GVHD prophylaxis. MMF (day -1 to day +28 , then taper) is added to CSA in unrelated donors only. Continuation or tapering of CSA and MMF is dependent on the presence or absence of GVHD.

8. Bone marrow is preferred as a stem cell source over PBSC because of its lower risk for GVHD.

9. For matched $(\geq 9 / 10)$ PBSC grafts, limitation of the total T cell dose of the unmanipulated graft or exvivo reduction of the $\mathrm{T}$ cell dose may be considered to avoid GVHD. For mismatched/ haploidentical $(<9 / 10)$ transplants, for $\mathrm{T}$ cell depletion is mandatory.

10. Haploidentical transplantation concepts in FA are under development; no specific concept can be favored over another at this time.

11. Because CBT in FA is still evolving, unrelated cord blood as a stem cell source is not generally recommended for transplantation of FA patients at this time.

12. Although most transplant experience stems from HSCTs conducted in children with FA, these recommendations are intended for pediatric and adult patients with the condition.

\section{Acknowledgements}

V

MMC, CK, and HH are supported by the Deutsche Kinderkrebsstiftung. The GEFA Registry is supported by the Deutsche Fanconi Anämie Hilfe e.V. HH and CPK are supported by the Aktionskreis Fanconi-Anämie e. V. and the Fanconi-Anämie-Stiftung.

Conflict of interest: The authors have no conflict of interest to disclose.

\footnotetext{
Affiliations

Pediatric Hematology/Oncology, Hannover Medical School, Hannover, Germany

Pediatric Hematology/Oncology and Stem Cell Transplantation,

Charité University Medicine Berlin, Berlin, Germany

Zentrum für Kinder- und Jugendmedizin, Klinikum der Johann-Wolfgang-

Goethe-Universität, Klinik III, Frankfurt, Germany

Pediatric Hematology/Oncology, University of Muenster, Muenster,

Germany

Pediatric hematology/Oncology, University Children's Hospital Tuebingen,

Tuebingen, Germany

Department of Pediatrics, Indiana University School of Medicine,

Indianapolis, IN, USA

Department of Otorhinolaryngology and Head/Neck Surgery, Heinrich

Heine University, Düsseldorf, Germany

Institute of Cellular Therapeutics, Hannover Medical School, GMP-DU,

IFB-Tx, Hannover, Germany

Paediatric Hematology and Oncology, Medical Center, University of Essen, Essen, Germany

Department of Pediatric Hematology Oncology, University of Düsseldorf

Medical School, Düsseldorf, Germany

Pediatric Hematologie/Oncology, University Medical Center

Hamburg-Eppendorf, Hamburg, Germany

Childrens Hospitals, University of Würzburg, Germany

Univ.-Klinik für Kinder- und Jugendmedizin, Ulm, Germany

Pediatric Hematology and Oncology, University Freiburg, Freiburg, Germany

Hematology/Onkology, Hannover Medical School, Hannover, Germany
} 


\section{References}

1 Ayas $M$, Al-Seraihi A, El-Solh $\mathrm{H}$ et al. The Saudi experience in fludarabine-based conditioning regimens in patients with Fanconi anemia undergoing stem cell transplantation: excellent outcome in recipients of matched related stem cells but not in recipients of unrelated cord blood stem cells. Biology of blood and marrow transplantation: journal of the American Society for Blood and Marrow Transplantation 2012: 18: 627-632

2 Ayas M, Saber W, Davies SM et al. Allogeneic hematopoietic cell transplantation for fanconi anemia in patients with pretransplantation cytogenetic abnormalities, myelodysplastic syndrome, or acute leukemia. J Clin Oncol 2013; 31: 1669-1676

3 Ayas $M$, Siddiqui $K$, Al-Jefri A et al. Factors Affecting the Outcome of Related Allogeneic Hematopoietic Cell Transplantation in Patients with Fanconi Anemia. Biology of blood and marrow transplantation: journal of the American Society for Blood and Marrow Transplantation 2014, doi: $10.1016 /$ j.bbmt.2014.06.016

4 Baker JM, Lewis VA, Fernandez CV et al. Allogeneic hematopoietic stem cell transplantation of patients with FA and high risk features using fludarabine without radiation. Pediatr Blood Cancer 2009; 52: 683-685

5 Bastien JP, Roy J, Roy DC. Selective T-cell depletion for haplotype-mismatched allogeneic stem cell transplantation. Seminars in oncology 2012; 39: 674-682

6 Beatty PG, Clift RA, Mickelson EM et al. Marrow transplantation from related donors other than HLA-identical siblings. The New England journal of medicine $1985 ; 313: 765-771$

7 Bertz $H$, Spyridonidis A, Wasch $R$ et al. A novel GVHD-prophylaxis with low-dose alemtuzumab in allogeneic sibling or unrelated donor hematopoetic cell transplantation: the feasibility of deescalation. Biology of blood and marrow transplantation: journal of the American Society for Blood and Marrow Transplantation 2009; 15: 1563-1570

8 Bitan M, Or R, Shapira MY et al. Fludarabine-based reduced intensity conditioning for stem cell transplantation of Fanconi anemia patients from fully matched related and unrelated donors. Biology of blood and marrow transplantation: journal of the American Society for Blood and Marrow Transplantation 2006; 12: 712-718

9 Bokhari S, Das-Gupta E, Russell $N$ et al. Post-transplant lymphoproliferative disease following reduced intensity conditioning transplants incorporating alemtuzumab. Bone marrow transplantation 2008; 42 : 281-282

10 Bonfim $C$, Ribeiro $L L$, Bitencourt $M$ et al. Long Term Follow up After Hematopoietic Stem Cell Transplantation for Fanconi Anemia: Analysis of 126 Pts Surviving More Than 2 Years After Transplant. ASH Annual Meeting Abstracts 2012; 120: 3079

11 Bonfim CM, de Medeiros CR, Bitencourt MA et al. HLA-matched related donor hematopoietic cell transplantation in 43 patients with Fanconi anemia conditioned with $60 \mathrm{mg} / \mathrm{kg}$ of cyclophosphamide. Biology of blood and marrow transplantation: journal of the American Society for Blood and Marrow Transplantation 2007; 13: 1455-1460

12 Boulad F, Davies SM, Williams DA et al. Chemotherapy-Only Preparative Regimen for T-Cell Depleted Hematopoietic Stem Cell Transplantation of Patients with Fanconi Anemia From Alternative Donors. ASH Annual Meeting Abstracts 2012; 120: 3471

13 Chakraverty R, Orti G, Roughton Met al. Impact of in vivo alemtuzumab dose before reduced intensity conditioning and HLA-identical sibling stem cell transplantation: pharmacokinetics, GVHD, and immune reconstitution. Blood 2010; 116: 3080-3088

14 Dalle $J H$. HSCT for Fanconi anemia in children: factors that influence early and late results. Bone marrow transplantation 2008; 42:(Suppl 2) S51-S53

15 Deeg HJ. Socie G, Schoch G et al. Malignancies after marrow transplantation for aplastic anemia and fanconi anemia: a joint Seattle and Paris analysis of results in 700 patients. Blood 1996; 87: 386-392

16 Djuzenova $C$, Flentje $M$, Plowman PN. Radiation response in vitro of fibroblasts from a fanconi anemia patient with marked clinical radiosensitivity. Strahlenther Onkol 2004; 180: 789-797

17 Drobyski WR. Evolving strategies to address adverse transplant outcomes associated with T cell depletion. Journal of hematotherapy \& stem cell research 2000; 9: 327-337

18 Dufort G, Pisano S, Incoronato A et al. Feasibility and outcome of haploidentical SCT in pediatric high-risk hematologic malignancies and Fanconi anemia in Uruguay. Bone marrow transplantation 2012; 47 663-668

19 Ertem $M$, lleri $T$, Azik $F$ et al. Related donor hematopoietic stem cell transplantation for Fanconi anemia without radiation: a single center experience in Turkey. Pediatr Transplant 2009; 13: 88-95
20 Eyrich $M$, Winkler B, Schlegel PG et al. Stem Cell Tranplantation in Fanconi Anemia - Recent Advances with Alternative Donors. In: Schindler D. Hoehn H (eds.). Fanconi Anemia. Basel: Karger, 2007; 173-182

21 Eyrich $M$, Wollny $G$, Tzaribaschev $N$ et al. Onset of thymic recovery and plateau of thymic output are differentially regulated after stem cell transplantation in children. Biology of blood and marrow transplantation: journal of the American Society for Blood and Marrow Transplantation 2005; 11: 194-205

22 Falk $P M$, Herzog $P$, Lubens $R$ et al. Bone marrow transplantation between a histocompatible parent and child for acute leukemia. Transplantation 1978; 25: 88-90

23 Fanconi G. Familial constitutional panmyelocytopathy, Fanconi's anemia (F.A.). I. Clinical aspects. Seminars in hematology 1967; 4: 233-240

24 Geddes M. Storek J. Immune reconstitution following hematopoietic stem-cell transplantation. Best Pract Res Clin Haematol 2007; 20: 329-348

25 Gluckman E. Radiosensitivity in Fanconi anemia: application to the conditioning for bone marrow transplantation. Radiotherapy and oncology: journal of the European Society for Therapeutic Radiology and Oncology 1990; 18: (Suppl 1): 88-93

26 Gluckman E, Broxmeyer HA, Auerbach AD et al. Hematopoietic reconstitution in a patient with Fanconi's anemia by means of umbilicalcord blood from an HLA-identical sibling. The New England journal of medicine $1989 ; 321: 1174-1178$

27 Gluckman E, Devergie A, Dutreix J. Radiosensitivity in Fanconi anaemia: application to the conditioning regimen for bone marrow transplantation. Br J Haematol 1983; $54: 431-440$

28 Gluckman E, Devergie A, Schaison G et al. Bone marrow transplantation in Fanconi anaemia. British journal of haematology 1980; 45 : 557-564

29 Gluckman E, Rocha V, Ionescu I et al. Results of unrelated cord blood transplant in fanconi anemia patients: risk factor analysis for engraftment and survival. Biology of blood and marrow transplantation: journal of the American Society for Blood and Marrow Transplantation 2007: 13: 1073-1082

30 Group EEW. EBMT/ESID Guidelines for Haematopoietic Stem Cel Transplantation for Primary Immunodeficiencies. In: http://www. embt.org 2011; 2011

31 Guardiola P, Pasquini R, Dokal I et al. Outcome of 69 allogeneic stem cell transplantations for Fanconi anemia using HLA-matched unrelated donors: a study on behalf of the European Group for Blood and Marrow Transplantation. Blood 2000; 95: 422-429

32 Guardiola $P$, Socie $G$, Li X et al. Acute graft-versus-host disease in patients with Fanconi anemia or acquired aplastic anemia undergoing bone marrow transplantation from HLA-identical sibling donors: risk factors and influence on outcome. Blood 2004; 103: 73-77

33 Gungor $T$, Teira $P$, Slatter $M$ et al. Reduced-intensity conditioning and HLA-matched haemopoietic stem-cell transplantation in patients with chronic granulomatous disease: a prospective multicentre study. Lancet 2014; 383: 436-448

34 Hamidieh AA, Alimoghaddam $K$, Jahani $M$ et al. Long-term results of non-fludarabine versus fludarabine-based stem cell transplantation without total body irradiation in Fanconi anemia patients. Hematol Oncol Stem Cell Ther 2011; 4: 109-115

35 Handgretinger $R$. Negative depletion of CD3(+) and TcRalphabeta(+) T cells. Current opinion in hematology 2012; 19: 434-439

36 Jaing TH, Chen SH, Yang CP et al. Successful Hematopoietic Reconstitution by Unrelated Donor Cord Blood Transplantation in Children With Fanconi Anemia: Report of 3 Cases. Journal of pediatric hematology/ oncology 2014, doi: $10.1097 / \mathrm{mph} .0000000000000215$

37 Kalb $R$, Duerr $M$, Wagner $M$ et al. Lack of sensitivity of primary Fanconi's anemia fibroblasts to UV and ionizing radiation. Radiat Res 2004: 161: 318-325

38 Kanda J, Lopez RD, Rizzieri DA. Alemtuzumab for the prevention and treatment of graft-versus-host disease. International journal of hematology 2011; 93: 586-593

39 Kapelushnik J, Or R, Slavin S et al. A fludarabine-based protocol for bone marrow transplantation in Fanconi's anemia. Bone marrow transplantation 1997; 20: 1109-1110

40 Koenig $M$, Huenecke S, Salzmann-Manrique E et al. Multivariate analyses of immune reconstitution in children after allo-SCT: risk-estimation based on age-matched leukocyte sub-populations. Bone marrow transplantation 2010; 45: 613-621

41 Kutler DI, Singh B. Satagopan J et al. A 20-year perspective on the International Fanconi Anemia Registry (IFAR). Blood 2003; 101: 1249-1256 
42 Lang P, Feuchtinger T, Teltschik H-M et al. Transplantation Of TcR $\alpha \beta$ CD19 Depleted Stem Cells From Haploidentical Donors In Children: Current Results. Blood 2013; 122: 692-692

43 Lehmann LE, Williams DA, London WB et al. Full Donor Myeloid Engraftment with Minimal Toxicity in Dyskeratosis Congenita Patients Undergoing Allogeneic Bone Marrow Transplantation without Radiation or Alkylating Agents. 56th ASH Annual Meeting and Exposition; December 6-9.2014; San Francisco, CA

44 Locatelli F, Bauquet $A$, Palumbo $G$ et al. Negative depletion of alpha/ beta + T cells and of CD19+B lymphocytes: a novel frontier to optimize the effect of innate immunity in HLA-mismatched hematopoietic stem cell transplantation. Immunology letters 2013: 155: 21-23

45 MacMillan ML. Auerbach AD, Davies SM et al. Haematopoietic cell transplantation in patients with Fanconi anaemia using alternate donors: results of a total body irradiation dose escalation trial. $\mathrm{Br} J$ Haematol 2000; 109: 121-129

46 MacMillan ML, Blazar BR, Defor TE et al. Alternative Donor Hematopoietic Cell Transplantation for Patients with Fanconi Anemia. ASH Annual Meeting Abstracts 2012; 120: 3081

47 MacMillan ML, Blazar BR, DeFor TE et al. Alternate Donor HCT for Fanconi Anemia (FA): Results of a Total Body Irradiation (TBI) Dose De-Escalation Study. Biology of Blood and Marrow Transplant 15: 3-4

48 MacMillan ML. Wagner JE. Haematopoeitic cell transplantation for Fanconi anaemia - when and how? Br J Haematol 2010; 149: 14-21

49 Marcou Y, D'Andrea A, Jeggo PA et al. Normal cellular radiosensitivity in an adult Fanconi anaemia patient with marked clinical radiosensitivity. Radiotherapy and oncology: journal of the European Society for Therapeutic Radiology and Oncology 2001; 60: 75-79

50 Marsh JC, Pearce RM, Koh MB et al. Retrospective study of alemtuzumab vs ATG-based conditioning without irradiation for unrelated and matched sibling donor transplants in acquired severe aplastic anemia: a study from the British Society for Blood and Marrow Transplantation. Bone marrow transplantation 2014; 49: 42-48

51 Medicine BCo. Antibody Conditioning Regimen for Allogeneic Donor Stem Cell Transplantation of Patients with Fanconi Anemia. In 2013;

52 Oevermann $L$, Handgretinger $R$. New strategies for haploidentical transplantation. Pediatric research 2012; 71: 418-426

53 Oevermann L, Lang P. Feuchtinger $T$ et al. Immune reconstitution and strategies for rebuilding the immune system after haploidentical stem cell transplantation. Annals of the New York Academy of Sciences 2012; 1266: 161-170

54 Pasquini $R$, Carreras J, Pasquini MC et al. HLA-matched sibling hematopoietic stem cell transplantation for fanconi anemia: comparison of irradiation and nonirradiation containing conditioning regimens. Biology of blood and marrow transplantation: journal of the American Society for Blood and Marrow Transplantation 2008; 14: 1141-1147

55 Peffault de Latour $R$, Porcher $R$. Dalle JH et al. Allogeneic hematopoietic stem cell transplantation in Fanconi anemia: the European Group for Blood and Marrow Transplantation experience. Blood 2013; 122: 4279-4286

56 Perlingeiro Beltrame M. Malvezzi M, Bonfim C et al. Immune reconstitution in patients with Fanconi anemia after allogeneic bone marrow transplantation. Cytotherapy $2014 ; 16: 976-989$

57 Poire $X$, van Besien $K$. Alemtuzumab in allogeneic hematopoetic stem cell transplantation. Expert Opin Biol Ther 2011; 11: 1099-1111
58 Powles RL, Morgenstern GR, Kay HE et al. Mismatched family donors for bone-marrow transplantation as treatment for acute leukaemia. Lancet 1983; 1: 612-615

59 Rosenberg PS, Socie G, Alter BP et al. Risk of head and neck squamous cell cancer and death in patients with Fanconi anemia who did and did not receive transplants. Blood 2005; 105: 67-73

60 Scheckenbach $K$, Morgan M, Filger-Brillinger J et al. Treatment of the bone marrow failure in Fanconi anemia patients with danazol. Blood Cells Mol Dis 2012; 48: 128-131

61 Shah AJ, Kapoor N, Crooks GM et al. The effects of Campath $1 \mathrm{H}$ upon graft-versus-host disease, infection, relapse, and immune reconstitution in recipients of pediatric unrelated transplants. Biology of blood and marrow transplantation: journal of the American Society for Blood and Marrow Transplantation 2007; 13: 584-593

62 Shimada A, Takahashi Y, Muramatsu $\mathrm{H}$ et al. Excellent outcome of allogeneic bone marrow transplantation for Fanconi anemia using fludarabine-based reduced-intensity conditioning regimen. International journal of hematology 2012; 95: 675-679

63 Socie G, Gluckman E, Raynal B et al. Bone marrow transplantation for Fanconi anemia using low-dose cyclophosphamide/thoracoabdominal irradiation as conditioning regimen: chimerism study by the polymerase chain reaction. Blood 1993; 82: 2249-2256

64 Soiffer RJ. Lerademacher J, Ho V et al. Impact of immune modulation with anti-T-cell antibodies on the outcome of reduced-intensity allogeneic hematopoietic stem cell transplantation for hematologic malignancies. Blood 2011; 117: 6963-6970

65 Stepensky P, Shapira MY, Balashov D et al. Bone marrow transplantation for Fanconi anemia using fludarabine-based conditioning. Biology of blood and marrow transplantation: journal of the American Society for Blood and Marrow Transplantation 2011; 17: 1282-1288

66 Thakar MS, Bonfim C, Sandmaier BM et al. Cyclophosphamide-based in vivo T-cell depletion for HLA-haploidentical transplantation in Fanconi anemia. Pediatr Hematol Oncol 2012; 29: 568-578

67 Thakar MS, Kurre P, Storb Ret al. Treatment of Fanconi anemia patients using fludarabine and low-dose TBI, followed by unrelated donor hematopoietic cell transplantation. Bone marrow transplantation 2011: 46: 539-544

68 Wagner JE, Eapen M, MacMillan ML et al. Unrelated donor bone marrow transplantation for the treatment of Fanconi anemia. Blood 2007; 109: 2256-2262

69 Wang $L$, Romero M, Ratajczak P et al. Increased apoptosis is linked to severe acute GVHD in patients with Fanconi anemia. Bone marrow transplantation 2013; 48: 849-853

70 Yabe $M$, Shimizu $T$, Morimoto $T$ et al. Matched sibling donor stem cell transplantation for Fanconi anemia patients with T-cell somatic mosaicism. Pediatr Transplant 2012; 16: 340-345

71 Yesilipek MA, Karasu GT, Kupesiz A et al. Better post transplant outcome with fludarabine based conditioning in multitransfused fanconi anemia patients who underwent peripheral blood stem cell transplantation. Journal of pediatric hematology/oncology 2009; 31: 512-515

72 Zecca M, Strocchio L, Pagliara D et al. HLA-haploidentical T cell-depleted allogeneic hematopoietic stem cell transplantation in children with Fanconi anemia. Biology of blood and marrow transplantation: journal of the American Society for Blood and Marrow Transplantation $2014 ; 20: 571-576$ 